\title{
The relationship between embb306 and embb406 mutations and ethambutol resistant in Mycobacterium tuberculosis isolated from patiens in west of Iran
}

\author{
Bahman Mohammadi ${ }^{1}$, Parviz Mohajeri ${ }^{2}$, Samaneh Rouhi ${ }^{1,3}$, Rashid Ramazanzadeh*3, 4
}

Received: 17 Mar $2017 \quad$ Published: 24 Nov 2018

\begin{abstract}
Background: Mutations in embB gene have been reported in ethambutol (EMB) resistance Mycobacterium tuberculosis (M. tuberculosis) isolates. The aim of this study was survey on embB 306 and 406 EMB resistant M. tuberculosis isolated from patients in West of Iran (2014-2015).

Methods: Fifty strains of M. tuberculosis from patients with pulmonary tuberculosis (TB) were considered. Drug susceptibility using proportional method was performed. Polymerase chain reaction (PCR) -DNA sequencing was applied for mutation in $e m b \mathrm{~B} 306$ and 406 codon detection. Data were analyzed in SPSS 16 software using descriptive statistics and Fisher's exact test $(\mathrm{p}<0.05)$.

Results: In this study 7 (14\%) M. tuberculosis isolates were resistant to EMB. $6(85.71 \%)$ and $1(14.28 \%)$ resistant isolates had embB 306 and 304 codon mutations, respectively. Between embB306 mutations and resistance to EMB and MDR isolates had a significant relationship $(\mathrm{p}<0.001)$.

Conclusion: The data indicated that $e m b \mathrm{~B} 306$ mutations have effect on EMB resistant. Detection of EMB resistant and these mutations prominent for antibiotic prescription.
\end{abstract}

Keywords: embB gene, Mutations, Ethambutol Resistance, Mycobacterium tuberculosis

Conflicts of Interest: None declared

Funding: Research Deputy of Kurdistan University of Medical Sciences, Kurdistan, Iran

*This work has been published underCC BY-NC-SA 1.0 license.

Copyright $₫$ Iran University of Medical Sciences

Cite this article as: Mohammadi B, Mohajeri $\mathrm{P}$, Rouhi S, Ramazanzadeh R. The relationship between embb306 and embb406 mutations and ethambutol resistant in Mycobacterium tuberculosis isolated from patiens in west of Iran. Med J Islam Repub Iran. $2018(24$ Nov);32:117. https://doi.org/10.14196/mjiri.32.117

\section{Introduction}

Ethambutol (EMB) is one of the first-line drugs that used in the treatment of tuberculosis (TB). Mutations in the $e m b \mathrm{~B}$ gene codons have effects on the resistance to EMB. Mutations in $e m b \mathrm{~B}$ gene, especially those in the EMB resistance-determining region (ERDR), are considered as "hot-spots". These mutations in different embB gene codon have been frequently reported in EMBresistant Mycobacterium tuberculosis (M. tuberculosis)isolates $(1,2)$. In many studies, substitution in different

Corresponding author:Dr Rashid Ramazanzadeh,atrop_t51@yahoo.com or rashid@muk.ac.ir

1. Student Research Committee, Kurdistan University of Medical Sciences, Sanandaj, Iran

2. Department of Microbiology, School of Medicine, Kermanshah University of Medical Sciences, Kermanshah, Iran

3. Cellular and Molecular Research Center, Research Institute for Health Development, Kurdistan University of Medical Sciences, Sanandaj, Iran

4. Department of Microbiology, School of Medicine, Kurdistan University of Medical Sciences, Sanandaj, Iran codon of $e m b \mathrm{~B}$ gene has been considered as the main position for EMB resistance. BakuBa et al. (2013) in Poland using sequence analysis and polymerase chain reaction (PCR) reported in 17 EMB resistant M. tuberculosis isolates, mutations in codon 306 were most common and found in 9 (52.94\%) EMB-resistant isolates (2). Bahrami et al. (2013) using multiplex allele-specific (MAS)-PCR from $176 \mathrm{M}$. tuberculosis isolates, 48 isolates were found to be resistant to EMB and in the 14 EMB resistant cases,

$\uparrow$ What is "already known" in this topic:

There are considerations on relationship between mutations that was occurred in embb306 and embb406 genes that lead to ethambutol and MDR resistant in Mycobacterium tuberculosis isolated from patients with TB.

$\rightarrow$ What this article adds:

This study, proved occurrence of embB306 mutations in EMBresistant $M$. tuberculosis isolates. A screening using molecular tools in laboratory for EMB-resistant and MDR M. tuberculosis that isolated from patients with TB is necessary before drug prescription. 
mutation was found third base of the codon 306 ATG (3). Also Cuevas-Cordoba et al. (2015) in Mexico by sequence analysis and PCR reported that mutation at embB codon 306 in resistance $M$. tuberculosis associated with EMB was related with resistant (4). It is very important to evaluate the prevalence of specific mutations associated with resistance to EMB. The aim of this study was to evaluate the frequency of point mutations (hot spots) in $e m b \mathrm{~B}$ gene among $M$. tuberculosis isolates in the West of Iran during 2014 to 2015.

\section{Methods}

This cross-sectional survey was done on smear-positive of patients that referred to TB research center in Kermanshah city, Kermanshah Province, west of Iran, during 2014-2015 years.

\section{Sampling}

Out of the 1069 strains of M. tuberculosis, 50 strains from patients with pulmonary TB (22 men and 28 women with the age range of 23-86 and a median age of 54.5 years) were included in this study and evaluated. At first decontamination method (Modified Petroff) was performed on the samples and then they were stained using the Ziehl-Nelson staining method for observation. In other hand, samples were cultured on Lowenstein-Jensen agar media (Merck, Germany) and incubated for four weeks at $37^{\circ} \mathrm{C}$. Colonies were tested with biochemical tests as catalase, nitrate, niacin, pigment production, and colony growth rate.

\section{Drug susceptibility test}

Drug susceptibility testing of M. tuberculosis (the proportional method) was done according to the standards of mycobacteriological procedures for isoniazid (INH) $(0.2$ $\mu \mathrm{g} / \mathrm{ml})$, rifampin (RIF) $(40 \mu \mathrm{g} / \mathrm{ml})$, streptomycin (STR) (4 $\mu \mathrm{g} / \mathrm{ml})$, and EMB $(2 \mu \mathrm{g} / \mathrm{ml})$. The H37RV reference strain of $M$. tuberculosis was served as quality control for EMB susceptibility testing (5).

\section{Polymerase Chain Reaction (PCR) technique}

Bacteria that were cultured on Lowenstein-Jensen media were deactivated in the temperature $80^{\circ} \mathrm{C}$ for one hour. Then DNAs were extracted with the cetyl-trimethyl ammonium bromide (CTAB) method. For EMB-resistant and susceptible isolates, an 863-bp fragment from the ERDR of the $e m b B$ gene was PCR-amplified. The oligonucleotide primers embB F (5'-CGACGCCGTGGTGA TATTCG-3') and embB R (5'-CCACGCTGGGAATTC GCTTG-3') were used as described previously (2).

\section{Sequencing}

For all the samples $(50 ; 100 \%)$ that had $863 \mathrm{bp}$ band in the electrophoresis, nucleotide sequencing was performed for $e m b \mathrm{~B} 306$ and 406 codon mutations detection automatically (by Macro Gene, a Korean company). The sequence data were analyzed with the Chromas Pro ver. 1.7.1 software program. The nucleotide sequences were translated to amino acids using the European Bioinformatics Institute (EMBL-EBI) website (http://www.ebi.ac.uk/
Tools/psa/emboss_needle/index.html). The existence of mutations was determined by comparing the achieved sequences with the $M$. tuberculosis reference strain H37Rv (ATCC 27294) sequence of $e m b$ B from the GenBank database (www.ncbi.nlm. nih.gov/genbank/) using the BLASTn algorithm (blast.ncbi.nlm.nih.gov/).

\section{Statically method}

Data were analyzed using SPSS 16 software. Descriptive statistics to determine the frequency and percentage and also Fisher's exact test to compare qualitative findings were used $(\mathrm{p}<0.05)$.

\section{Results}

\section{Drug susceptibility test result}

Drug susceptibility proportional method results showed that of $50 \mathrm{M}$. tuberculosisisolates, only 17 (86\%) strains were sensitive to all drugs, $8(16 \%)$ of strains were multidrug resistant (MDR) and $25(50 \%)$ were non-MDR. Also $7(14 \%)$ and $43(86 \%)$ M. tuberculosisisolates were resistant and suspect to EMB, respectively. 5 (71.42\%) EMB-resistant $(100 \%) M$. tuberculosis isolates were in MDR and 2 (28.57\%) were in non-MDR group. From 43 nonresistant EMB isolates, $17(39.53 \%)$ were found in sensitive to all drugs group and $23(53.48 \%)$ were in nonMDR group and 3 (6.97\%) samples in MDR group.

\section{Polymerase Chain Reaction (PCR) technique test}

PCR results confirmed $e m b \mathrm{~B}$ gene for all 50 samples (Fig. 1).

\section{Sequencing results}

Also PCR-DNA sequencing forembB 306 and 406 codon showed that in EMB susceptible strains, mutations at the $e m b \mathrm{~B} 306$ codon were not detected. But embB 306 codon point mutation in $6(85.71 \%)$ and $e m b \mathrm{~B} 406$ codon point mutation in $1(14.28 \%)$ of EMB resistant isolates were found (Table 1, Fig. 2).

Statistical results showed that embB306 mutations and resistance to $\mathrm{EMB}$ and $\mathrm{MDR}$ had a direct relationship with each other $(\mathrm{p}<0.001)$.

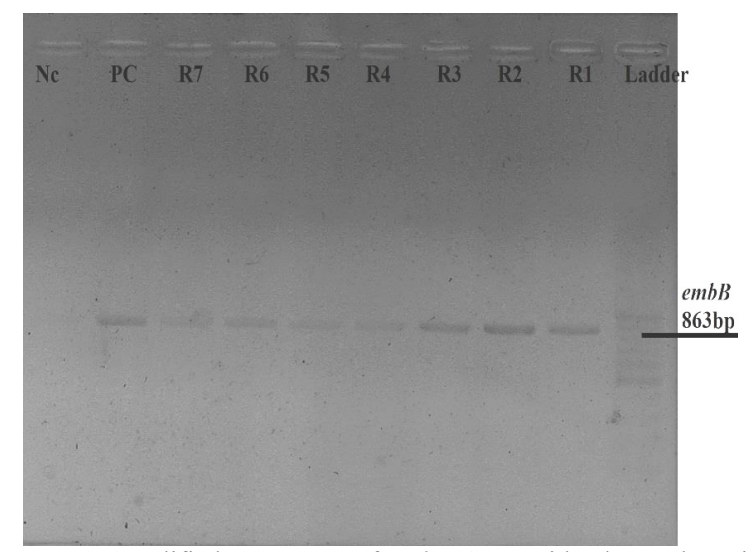

Fig. 1. Amplified Fragments of embB Gene with Electrophoresis of PCR products in M. tuberculosis isolates; Line 1, Ladder (100$1500 \mathrm{bp})$; Line 2-8, embB gene in EMB resistance samples (863bp); Line 9, Positive control; Line 10, Negative control. 
Table 1.Point mutation in EMB-resistant and EMB-susceptible M. tuberculosis isolates

\begin{tabular}{|c|c|c|c|}
\hline \multirow[t]{2}{*}{ Nucleotide } & \multirow{2}{*}{$\begin{array}{l}\text { Mutation }{ }^{*} \\
\text { Aminoacid }\end{array}$} & \multicolumn{2}{|c|}{ No. (\%) of isolates mutation } \\
\hline & & EMB-resistant $(\mathrm{n}=7)$ & EMB-susceptible $(n=43)$ \\
\hline $\mathrm{ATG} \rightarrow \mathrm{ATA} \underline{\mathrm{A}}$ & Met $\rightarrow$ IL (306) & $3(42.85)$ & $0(0)$ \\
\hline$\underline{\mathrm{ATG}} \rightarrow \underline{\mathrm{GTG}}$ & Met $\rightarrow$ Val (306) & $3(42.85)$ & $0(0)$ \\
\hline$\underline{\overline{\mathrm{G}} \mathrm{GC}} \rightarrow \underline{\overline{\mathrm{A}} \mathrm{GC}}$ & Gly $\rightarrow$ Ser $(406)$ & $1(14.28)$ & $0(0)$ \\
\hline
\end{tabular}

\begin{tabular}{|c|c|c|}
\hline P337623.1_1 & $\theta 1$ & AVSATIDTRFSTRPTTLKLLAIIGAIVATWAL IALWRLDQLDGRGSIAQ \\
\hline R1_embBR_1 & 1 & - vIGANSSDD \\
\hline KP337623.1_1 & 251 & LLLRPFRPASSPGGMRRLIPASWRTFTLTDAWIFGFLLWHVIGANSSDD \\
\hline R1_embBR_1 & 10 & $\begin{array}{l}\text { GYILGIARVADHAGYMSNYFRWFGSPEDPFGWYLLALMTHVSDASLWM } \\
|||||||||||||||||||||||||||||||||||||||||||||||||| l \mid\end{array}$ \\
\hline KP337623.1_1 & 301 & GYILGMARVADHAGYMSNYFRWFGSPEDPFGWMLLALMTHVSDASL WM \\
\hline R1_embBR_1 & 60 & 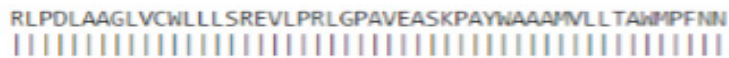 \\
\hline KP337623.1_1 & 351 & RLPDLAAGLVCWLLLSREVLPRLGPAVEASKPAYWAAAMVLLTAWWPFNN \\
\hline R1_embBR_1 & 110 & 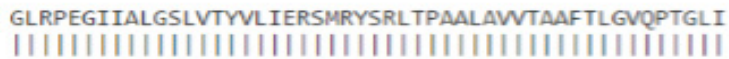 \\
\hline KP337623.1_1 & 401 & GLRPEGIIALGSLVTVVI IERSMRYSRLTPAAL AVVTAAFTLGVQPTGLI I \\
\hline R1_embBR_1 & 160 & 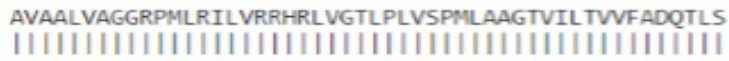 \\
\hline KP337623.1_1 & 451 & AVAALVAGGRPMLRILVRRHRLVGTLPLVSPMLAAGTVILTVVFADQTLS \\
\hline R1_embBR_1 & 210 & $\begin{array}{l}\text { TVLEATRVRAKIGPSQAWYTENLRYYLILPTVDGSLSRRFG } \\
||||||||||||||||||||||||||||||||||||||\end{array}$ \\
\hline KP337623.1_1 & 501 & TVLEATRVRAKIGPSQAUYTENL RYYYLILPTVDGSLSRRFGFLITALCL \\
\hline R1_embBR_1 & 252 & $\ldots$ \\
\hline KP337623.1_1 & 1 & TAVFIMLRRKRIPSVARGPAWRLMGVIFGTMFFLMFTPTKWVHHFGLFA \\
\hline
\end{tabular}

Fig. 2.Amino acid sequence compared to H37RV in (EMBL-EBI) with nBLAST algorithms, mutation amino acid isoleucine (I) instead of methionine (M) at codon 306

\section{Discussion}

EMB resistance is a serious problem in many countries, so early detection of EMB resistance is very important to avoid of resistant strains spread (6). In our study, $86 \%$ of strains were sensitive to all antibiotics that were applied. But $16 \%$ of strains were MDR, also $50 \%$ were non-MDR. In a study in 2015 in Iran, Tavanaee Sani et al. using standard proportional method showed MDR-TB in 56 new cases $(1.78 \%)$ and $26(11.53 \%)$ patients with relapse during 2012-2013 that it was less than our study. Different rate of resistant can be due to obtaining sample from restricted regions with low or high rate of resistance. For example high rate of resistance can be observed in neighboring of region such as Afghanistan and Pakistan as the most prevalent area for TB (7). In our results, $14 \%$ of $M$. tuberculosis isolates in our results were related with EMB resistant. In other hand PCR-DNA sequencing proved that in all EMB resistant isolates point mutation were occurred. embB 306 codon mutations in $85.71 \%$ and $e m b \mathrm{~B}$ 406 codon mutation in $14.28 \%$ of EMB resistant isolates were found. Nasr Esfahani et al. in Iran in 2016 using standard proportional method reported from $32 \mathrm{M}$. tuberculosis isolates, $6.25 \%$ were resistant to EMB. PCR- Single-strand conformation polymorphism (SSCP) and direct sequencing in Nasr Esfahani Esfahani study detected 2 EMB resistant isolates had mutation in codons 309 and 299 (8). Prevalence of EMB resistant isolates with mutation in our work is higher than Nasr Esfahani study. $M$. tuberculosis has different mechanisms to ovoid killed by drugs. One of these mechanisms is mutations in embB gene. This gene encodes an arabinosyltransferase that is involved in cell wall arabinan biosynthesis and it is the target for the EMB. Mutation in this gene causes EMB resistant (9). Mour et al. in 2014 in Spain reported that from 53 strains resistant to EMB, $77.4 \%$ of strains had mutation substitutions in the $e m b \mathrm{~B}$ gene. $53.7 \%$ of them were related to codon 306 and $26.8 \%$ strains showed mutation in codon406. Mutations in $e m b \mathrm{~B} 406$ were related to EMB resistance and MDR (10). Also embB306 mutations in our study had a significant relationship with EMB resistant and MDR strains. M. tuberculosis is a human pathogen that causes TB and this disease damages the lungs, central nervous system, lymphatic system and circulatory system. So a prevention and appropriate management in treatment for this infection is necessary $(11,12)$.

\section{Conclusion}

In conclusion, the results presented in this study suggest that the frequency of embB306 mutations in EMBresistant $M$. tuberculosis isolates, is much higher than its occurrence in EMB-susceptible isolates. These results suggest that the sequencing of this region of $e m b \mathrm{~B}$ gene is sufficiently sensitive to be used as a fast screening tool for finding high-level resistance to EMB, specifically in the population served by our research laboratory.

\section{Acknowledgement}

This article is part of MSc medical microbiology student 
thesis Bahman Mohammadi (code: 1394/65). The authors wish to extend their gratitude to the Research Deputy of Kurdistan University of Medical Sciences for financial support. We thank of Mrs. Sara Atashi, Pegah Shakib and Mr. Galini for their excellent technical assistance.

Financial support for this study was provided by Research Deputy of Kurdistan University of Medical Sciences, Kurdistan, Iran.

\section{Conflict of Interests}

The authors declare that they have no competing interests.

\section{References}

1. Ramazanzadeh R, Roshani D, Shakib P, Rouhi S. Prevalence and occurrence rate of Mycobacterium tuberculosis Haarlem family multidrug resistant in the worldwide population: A systematic review and meta-analysis. J Res Med Sci. 2015 Jan 1;20(1):78-88.

2. Bakula Z, Napiorkowska A, Bielecki J, Augustynowicz-Kopec E, Zwolska Z, Jagielski T. Mutations in the embB gene and their association with ethambutol resistance in multidrug-resistant Mycobacterium tuberculosis clinical isolates from Poland. BioMed Res. 2013 Dec 11;2013(2013):1-6.

3. Bahrami S, Bahrmand AR, Safarpour E, Masoumi M, Saifi M. Detection of ethambutol-resistant associated mutations in Mycobacterium tuberculosis isolates from Iran using multiplex allelespecific PCR. J Med Microbiol Infec Dis. 2013 Sep 26;1(1):41-5.

4. Cuevas-Cordoba B, Juarez-Eusebio DM, Almaraz-Velasco R, MuoizSalazar R, Laniado-Laborin R, Zenteno-Cuevas R. Mutation at embB codon 306 , a potential marker for the identification of multidrug resistance associated with ethambutol in Mycobacterium tuberculosis. Antimicrob Agents Chemother. 2015 Jun 29;59(9):5455-62.

5. Sahebi L, Ansarin KH, Hoffner S, Mohajeri P, Mohammadi A. Beijing strains of Mycobacterium tuberculosis in smear-positive tuberculosis patients in North-West and West of Iran. Adv Biomed Res. 2016 Nov 28;5(2016):181.

6. Yoon JH, Nam JS, Kim KJ, Ro YT. Simple and rapid discrimination of embB codon 306 mutations in Mycobacterium tuberculosis clinical isolates by a real-time PCR assay using an LNA-TaqMan probe. J Microb Method. 2013 Dec 28;92(3):301-6.

7. Tavanaee Sani A, Shakiba A, Salehi M, Bahrami Taghanaki HR, Ayati Fard SA, Ghazvini K. Epidemiological Characterization of Drug Resistance among Mycobacterium tuberculosis Isolated from Patients in Northeast of Iran during 2012-2013. Biomed Res Int. 2015 May 3; 2015(2015):1-6.

8. Esfahani BN, Zarkesh FS, Rezaei Yazdi H, Radaee T. Detection of embB gene mutations in EMB-resistant Mycobacterium tuberculosis isolates from Isfahan province by PCR-SSCP and direct sequencing. Jundishapur J Microbiol. 2016 Sep 26;9(12):e39594.

9. Xu Y, Jia $\mathrm{H}$, Huang $\mathrm{H}$, Sun $\mathrm{Z}$, Zhang Z. Mutations Found in embCAB, embR, and ubiA Genes of Ethambutol-Sensitive and Resistant Mycobacterium tuberculosis Clinical Isolates from China. BioMed Res Int. 2015 Aug 19;2015(2015):1-8.

10. Moure R, Espanol M, Tudo G, Vicente E, Coll P, Gonzalez-Martin $\mathrm{J}$, et al. Characterization of the embB gene in Mycobacterium tuberculosis isolates from Barcelona and rapid detection of main mutations related to ethambutol resistance using a low-density DNA array-authors' response. J Antimicrob Chemother. 2014;69:2299-300.

11. Babamahmoodi F, Alikhani A, Yazdani Charati J, Ghovvati A, Ahangarkani F, Delavarian L, et al. Clinical epidemiology and paraclinical findings in tuberculosis patients in north of Iran. Biomed Res Int. 2015;2015:1-5.

12. Rezai MS, Ahangarkani F , Sadeghi R, Mahdavi MR. Evaluation of children with complication of bcg vaccination in north of Iran. Int J Pediatr. 2017 Mar 1;5(3):1795-805. 